\title{
Ghrelin function in human obesity and type 2 diabetes: A
}

\section{concise review.}

Churm $\mathrm{R}^{1}$, Davies $\mathrm{JS}^{2}$, Stephens $\mathrm{JW}^{1}$, Prior $\mathrm{SL}^{1}$

${ }^{1}$ Diabetes Research Group, Institute of Life Science 1, Swansea University, Swansea, UK

${ }^{2}$ Molecular Neurobiology Research Group, Institute of Life Science 1, Swansea University, Swansea, UK

Running title

Ghrelin in human obesity and diabetes

\section{Key words}

Ghrelin, Obesity, Type 2 diabetes

\section{Acknowledgements}

I would like to acknowledge Health and care research Wales (HS-14-40) for funding this work.

\section{Conflicts of interest}

None.

\section{Correspondence}

Ms Rachel Churm

Tel: +44(0)1792 602310

Email:656073@swansea.ac.uk 


\section{Abstract}

The 28 amino acid hormone, ghrelin has been found to have various effects on metabolism. This review will focus on the pathways integrated into ghrelin's effect within the hypothalamus, pancreas and adipocytes. The identification of molecules and pathways that regulate ghrelin mediated lipid retention could establish new mechanisms underlying cellular energy homeostasis. The impact of acyl-ghrelin on glucose metabolism and lipid homeostasis may allow for novel preventative or early intervention therapeutic strategies to treat obesity related type 2 diabetes and associated metabolic dysfunction. 


\section{Introduction}

Type 2 diabetes mellitus (T2DM) and obesity are both chronic conditions associated with significant morbidity and mortality predominantly from associated chronic diseases. The World Health Organisation (WHO) states that obesity is a global epidemic, with over 1.9 billion obese adults. Obesity results from the dysregulation of energy expenditure resulting in an accumulation of white adipose tissue due to adipogenesis or lipid retention ${ }^{1}$. Therefore, the function of adipocytes, which includes the secretion of various hormones linked to the modulation of metabolism, is central to the development of obesity. A key hormone of interest, that is known to regulate cell proliferation and lipid retention, is the gastrointestinal peptide ghrelin ${ }^{2}$. The focus of this article is to review the mechanism(s) underlying ghrelin mediated lipid retention in adipocytes and its relevance to the aetiology of T2DM. The identification of new molecules modulating ghrelin mediated lipid retention in adipose tissue may be a therapeutic strategy for improving glucose homeostasis associated with obesity and T2DM.

\section{Ghrelin}

In 1999, Masayasu Kojima first described a 28 amino acid peptide hormone located in the stomach, with a distinctive $\mathrm{N}$-octanoylated serine 3 residue ${ }^{2}$. This peptide was named 'ghrelin', from the Latin word 'Ghre' which means 'grow' due to its role as a growth hormone releasing peptide ${ }^{2,3}$. The novel peptide was isolated from the gut of both human and rat as the endogenous ligand of the growth hormone secretagogue receptor (GHS-R) ${ }^{4}$. GHS-R is transcribed in humans from the growth hormone receptor 1 (GHR1) gene, which encodes the full length functional receptor (GHS-R1 $\alpha$ ) and a splice variant truncated non-functional isoform (GHS-R1 $\beta)^{5,6}$. GHS-R1 $\alpha$ mRNA is expressed at low levels over a wide tissue distribution but it predominantly expressed in the anterior pituitary gland ${ }^{5}$. The highest levels of ghrelin are secreted from the X/A- like cells of the oxyntic glands located in the

gastric fundus, with lower levels widely distributed throughout the body ${ }^{7,8}$. Ghrelin is secreted 
direct into the local gastric circulation and transported to the brain directly, requiring it to either cross the blood-brain barrier via a saturated transport system or via the blood stream to enter areas of the brain that are not protected by the blood brain barrier ${ }^{9}$. Ghrelin also modulates the hypothalamic arcuate nucleus (ARC), in an indirect manner, via activation of the vagus nerve and brain stem nuclei ${ }^{9,10}$. Ghrelin circulates in two major forms; acylated (approximately $5 \%$ of total ghrelin) and desacyl (95\% of total ghrelin) ${ }^{11}$. Previous work has demonstrated that the protein coding gene, membrane bound O-acyltransferase 4 (MBOAT4) is vital in the activation of ghrelin ${ }^{12}$. The human gene, MBOAT4 is located on chromosome 8 (8p12) and contains 6 exons. MBOAT4 transcribes a protein that was later termed ghrelin O-acyltransferase (GOAT), as this is the only enzyme known to post translationally acylate ghrelin. Both forms of ghrelin are observed to cross the barrier in a blood to brain direction. However, desacyl-ghrelin had reduced ability in crossing the barrier in a brain-blood direction ${ }^{13}$. Ghrelin's ability to cross the blood-brain barrier is the result of a combination of three systems; non-saturable, saturable blood-brain transport and saturable brainblood transport, all of which are dependent on the unique post translational acylation and primary structure ${ }^{13-15}$. In the last 16 years research has demonstrated that ghrelin has various peripheral effects and caused a great interest into the manipulation of the ghrelin system as a pharmacological tool. Ghrelin has a homeostatic role that encompasses multiple areas of the body, with actions that include; downregulation of brown adipose tissue thermogenesis ${ }^{16-18}$, modulation of nonhypothalamic brain regions producing an increased taste sensation ${ }^{19}$ and stimulation of gastric emptying and motility ${ }^{6,20}$. The actions of ghrelin may contribute to the development of T2DM and obesity $^{6}$ however this review will focus, in detail, on three main sites of ghrelin action; the hypothalamus, adipose tissue and the pancreas (Figure 1). 


\subsection{Ghrelin \& the hypothalamus}

\subsubsection{Obesity}

Ghrelin gene expression and plasma ghrelin levels change with food intake, such that in healthy humans acylated levels are elevated before feeding and decreased by feeding ${ }^{21-23}$. However, during prolonged fasting, plasma levels of acyl-ghrelin are not elevated and it is plasma desacyl-ghrelin levels that double ${ }^{24,25}$. Indeed, ghrelin is the only known gastrointestinal hormone whose concentration is increased in the blood following calorie restriction. Ghrelin is often termed 'the hunger hormone' and is an appetite stimulatory peptide ${ }^{26}$. The mechanism by which ghrelin stimulates feeding is well documented, the route of stimulation has been linked to ghrelin's activation of Neuropeptide $Y$ (NPY) neurons and agouti- related peptides (AGRP). NPY and AGRP containing neurons are located in the ARC where they are activated by elevation of intracellular calcium via phospholipase $\mathrm{C} /$ protein kinase $\mathrm{C}$ and adenylate cyclase/protein kinase $\mathrm{A}$ pathways ${ }^{27}$. In rodents, this calcium influx has also been linked to ghrelin's activation of phosphoinositide 3-kinase (PI3K) pathway due to the enhanced phosphorylation of Akt-Ser $473^{28}$. As well as the activation of orexigenic neurons, neurons containing anorexigenic peptides (pro-opiomelanocortin) are suppressed in the presence of ghrelin ${ }^{22,29,30}$. Ghrelin's role in stimulating feeding is reported to be the direct effect of circulating ghrelin on the hypothalamus, as orexigenesis is present without intact vagal afferent signalling ${ }^{31}$. However, there are reports suggesting that vagotomy does result in the loss of ghrelin's orexigenic function ${ }^{32}$. This indicates that peripheral ghrelin induces an eating stimulatory effect via an intertwined relationship involving the afferent vagus nerve and direct endocrine signalling. The cross comparison of published findings, with respect to ghrelin's paracrine vs endocrine signalling method, does require caution in interpretation as alternative results may represent varying methodologies. Several published studies have reported an association between ghrelin and obesity with a main focus on plasma ghrelin levels being negatively correlated with body mass index (BMI) ${ }^{29}$. As well as in obese patients, total ghrelin levels are reduced in obese patients with T2DM and levels does not fluctuate throughout the day. Therefore, the total ghrelin 
concentration does not return to baseline level as it does in lean patients after feeding ${ }^{11,33,34}$. The obese state has attenuated ghrelin levels resulting in abnormal hunger scores, upon the administration of acyl-ghrelin in humans, hunger profiles within obese subjects are returned to that of lean subjects ${ }^{35}$. The supressed level of ghrelin within diet induced obesity (DIO) can be linked to the decline in the expression of ghrelin and MBOAT4 in the stomach and GHS-R expression in the hypothalamus of mice ${ }^{36}$. DIO also has a detrimental effect on the neuroendocrine ghrelin system and causes ghrelin resistance in rodents through the down regulation and dysfunction of NPY/ AGRP neurons ${ }^{36}$. The apparent species-dependent discrepancy in DIO-induced ghrelin resistance warrants further research and may prevent the ghrelin system being a useful therapeutic target in $\mathrm{DIO}^{37}$.

\subsubsection{A role for ghrelin in human obesity?}

Obesity is a multifactorial disease and its origin can span from various avenues including genetics. Genetic factors are strongly associated with obesity and cover two areas, monogenic and polygenic factors. Prader- Willi syndrome (PWS) is a key example of genetic obesity and is the result of a loss of paternal genes in the q11-13 region of chromosome 15. Patients with PWS experience excessive appetite (hyperphagia) which is linked to hyperghrelinemia ${ }^{38}$. PWS patients have increased fasting and post prandial ghrelin levels when compared to non PWS obese or lean patients ${ }^{38}$. This indicates a potential role for ghrelin as a cause of hyperphagia and obesity in PWS due to either an increase in ghrelin gene expression, a decline in transcription inhibitory factors or a reduction in ghrelin clearance ${ }^{39}$. The inhibition of the ghrelin system may allow for the treatment of individuals diagnosed with PWS. This may be achieved by i) ghrelin immunization, ii) MBOAT4 or GOAT inhibition, or iii) antagonizing GHS-R.

Zorrilla et al, demonstrated that ghrelin immunization through a vaccine approach produced a significant reduction in weight through metabolic efficiency rather than altering hyerphagia ${ }^{40}$. Further immunizations were carried out through the use of Spiegelmers, a single stranded mirror image oglionucleotide which binds to ghrelin to decrease its half-life ${ }^{37,41}$. However, the use of 
Spiegelmers only generated weight reduction on a short term basis ${ }^{41}$. Preventing the acylation of ghrelin through either the reduction in MBOAT4 transcription or GOAT function will allow for a decrease in circulating acyl-ghrelin. The use of an antagonist of the GHS-R, [D-Lys ${ }^{3}$ GHRP-6, has been shown in male mice to allow for an increase in glycaemic control and decrease in body weight ${ }^{42}$. The reduction in glucose levels was mirrored by a decrease in insulin levels, indicating that GHS-R antagonism may be a therapeutic pathway for treating both obesity and insulin resistance ${ }^{42,43}$.

Controversially, an antagonist is only efficacious when blocking the action of an agonist, yet, as previously mentioned, the low levels of circulating ghrelin present in obese subjects may invalidate this approach. However, further work has led to the development of GHS-R1 $\alpha$ inverse agonists that work on the principle that GHS-R1 $\alpha$ signals $\sim 50 \%$ activity, independent of the presence of ghrelin ${ }^{44}$. The following inverse agonists; [D-Arg-1, D-Phe5, D-Trp7,9, Leu 11]- substance P, which prevent constitutive GHS-R1 $\alpha$ activity, were administered intracerebroventricularly in rats, resulting in a reduction in food intake and weight gain ${ }^{45}$. Han Lee, and colleagues also noted that the neuronal depletion of GHS-R abolished ghrelin-induced food intake and was detrimental to the development of $\mathrm{DIO}^{46}$. These finding indicate that GHS-R is a key modulator in energy metabolism and plays a role in DIO. We propose that further research is needed to elucidate the possible adipogenic and lipogenic role of constitutive GHS-R1 $\alpha$ signalling in the context of human obesity.

\subsection{Ghrelin \& Adipocytes}

\subsubsection{Adipogenesis}

Ghrelin is involved in the regulation of metabolic hormones, with GHS-R's present within adipose tissue ${ }^{4,47}$. In addition to stimulating growth hormone (GH) secretion and appetite, ghrelin has been shown to play a role in adiposity. Adipogenesis is a regulated process involving the differentiation of pre-adipocytes into mature adipocytes. This is controlled by specific transcription factors; peroxisome proliferator-activated receptor $\gamma($ PPAR $\gamma)$ and sterol-regulatory element binding protein- 
1 (SREBP1). SREBP1 is encoded by the SREBF1 gene which is transcribed into two splice variants, SREBP1-a and SREBP1-C ${ }^{48}$. Upon the addition of acyl-ghrelin and desacyl-ghrelin, PPARY and SREBF1 mRNA expression levels increase in human visceral adipocytes during differentiation ${ }^{11}$. Therefore, in the presence of ghrelin, in vitro and in vivo studies have demonstrated that mRNA levels of PPARY are increased resulting in the differentiation and proliferation of preadipocytes ${ }^{11}$. PPAR $\gamma$ activity can be influenced by key components that play a role in the mammalian insulin pathway, for example; mammalian target of rapamycin complex 1 (mTORC1) and the Akt/ Protein kinase B (Akt/PKB) complex ${ }^{27}$. In the presence of acyl-ghrelin, mTORC1 and Akt/PKB can enhance PPARy activation promoting adipogenesis ${ }^{27}$. The presence of mTORC1 and Akt/PKB highlights ghrelin's ability to have multifactorial effects, with the synergy of acyl-ghrelin's adipogenic effect and insulin signalling. Both desacyl and acyl-ghrelin produce an increase in adipogenesis and a decrease in insulin sensitivity, however desacyl-ghrelin's role is not consistent across studies (Table 1$)^{27}$. The elevation of SREBF1 was accompanied by a significant increase in lipid accumulation in visceral adipocytes ${ }^{11}$. This administration of ghrelin directly stimulated intracytoplasmic lipid accumulation via the increased production of various fat storage promoting enzymes including carboxylase, acetyl CoA, fatty acid synthase and lipoprotein lipase ${ }^{11}$.

\subsubsection{Lipid retention}

Following chronic intravenous administration in mice, ghrelin has also been shown to increase mRNA expression of genes which promote the retention of cholesterol ${ }^{49}$. The reverse cholesterol transport pathway, the removal of excess cholesterol from peripheral tissues back to the liver for excretion and catabolism, is critical due to the pathways role in defence against atherosclerosis ${ }^{50-52}$. This cholesterol efflux is dependent upon the ATP binding cassette (ABC)A1 and ABCG1 ${ }^{50,53}$. ABCG1 and $A B C A 1$ are members of a superfamily of transporters that functions to transport cholesterol to the cell surface for removal by high density lipoproteins $(H D L)^{50,52}$. PPARy induces the expression of $A B C$ via nuclear cholesterol sensors, liver $X$ receptors (LXR) i.e. LXR $\alpha$ and $\operatorname{LXR} \beta^{52}$. LXR acts as a 
transcription regulator for the genes associated with cholesterol efflux, which is activated when total cellular cholesterol levels are high ${ }^{54}$. However, when total cellular cholesterol levels are low, SREBP induces cholesterol biosynthesis ${ }^{54}$. So in the presence of ghrelin, SREBP1-c expression is increased whilst ABCG1 and LXR $\beta$ expression is decreased ${ }^{49}$. Even though these results indicate ghrelin has a role in increasing lipid retention within adipocytes, the relationship between cholesterol efflux, biosynthesis genes and ghrelin is disputed among studies. The hypothalamic activation of GHS-R1 $\alpha$ in mice and rats results in the activation of Sirtuin 1 (SIRT1) to deacetylate the tumour suppressor gene p53, increasing phosphorylation of AMP-activated protein kinase (AMPK) which in turn inactivates fatty acid biosynthesis and activates fatty acid oxidation ${ }^{55-57}$. In vivo, administration of ghrelin to p53 null mice demonstrates a decrease in lipid metabolism modulating gene expression i.e. SREBP1c, indicating that p53 is essential for the action of ghrelin on adipose tissue ${ }^{55}$. Ghrelin administration has also been reported to activate the PPARY-LXR-ABC pathway in a dose dependant manner, where ghrelin results in an increase in LXR and $A B C$ expression in human THP-1 macrophages ${ }^{58}$. An increase within cellular fat mass could result in an increase in lipogenesis and substrate uptake and a decrease in lipolysis and export ${ }^{1}$. These processes could alter the intrinsic regulation of free fatty acids and cholesterol biosynthesis pathways that could lead to hypertriglyceridemia and other complications ${ }^{59}$. Due to the diversity of published data and various doses of acyl-ghrelin administered, further research into ghrelin mediated lipid retention especially within humans is needed.

\subsection{Ghrelin \& the pancreas}

\subsubsection{Glucose homeostasis}

The process of glucose homeostasis is dependent on the liver and gut as sources for circulating glucose and adipose tissue as a peripheral organ for glucose utilisation. Ghrelin and GHS-R1 $\alpha$ RNAs are expressed within the pancreas and $\beta$-cells, suggesting a possible relation for ghrelin in affecting glucose homeostasis via insulin function. In humans acyl-ghrelin has direct metabolic actions at a 
peripheral level, influencing endopancreatic function and altering glucose's diabetogenic action ${ }^{60,61}$. As well as acyl-ghrelin, desacyl-ghrelin has been shown to alter glucose metabolism, the intravenous administration of desacyl-ghrelin in humans has been demonstrated to promote a favourable influence on glucose metabolism, insulin sensitivity and the inhibition of lipolysis ${ }^{60,}{ }^{61}$. The expression of GHS-R and ghrelin within the pancreas suggests local regulation of insulin secretion ${ }^{62}$, ${ }^{63}$, with acyl-ghrelin supressing insulin secretion both in vivo and in vitro. Dezaki and colleagues ${ }^{64}$ reported that endogenous acyl-ghrelin supresses insulin secretion via a restriction on glucose induced cytosolic calcium concentration and insulin release within islet $\beta$ cells of mice and rats. Furthermore, ghrelin inhibits glucose-induced membrane excitability, supressing cellular signalling ${ }^{64}$. However, the mechanism in which acyl-ghrelin regulates pancreatic islet function remains unclear with few studies in humans. Ghrelin's role in the attenuation of glucose stimulated insulin secretion was elucidated recently, indicating that ghrelin action on $\beta$ cells may be through a non-direct manner. DiGruccio and colleagues demonstrated that the presence of GHS-R1 on $\delta$ cells mediated indirect ghrelin action on $\beta$ cells ${ }^{65}$. Thus, GHS-R1a $\delta$ cells, promoted the secretion of intermediate products such as somatostatin through a calcium ion cascade that blocked insulin secretion ${ }^{65}$.

Studies in humans has shown that the acute intravenous administration of acyl-ghrelin via bolus injection and infusion are associated with an increase in plasma glucose levels in both healthy and obese patients, and this ghrelin mediated increase was seen to enhance second phase insulin response $^{8,26,66,67}$. In fasted mice this direct, non GH-mediated hyperglycaemic effect was blunted by the oral administration and intraperitoneal injection of a GHS-R antagonist, stabilising blood glucose levels ${ }^{68}$. Broglia et $a{ }^{26}$ noted that acyl-ghrelin's initial stimulation of somatostatin levels caused an inhibition of insulin release. Further work by Arosio and colleagues ${ }^{69}$ noted a similar relationship between acyl-ghrelin, somatostatin and glucose metabolism. However, the simultaneous rise in somatostatin and glucose indicates that ghrelin's effect on glucose metabolism is still unclear. The effect of ghrelin is suggested to be direct yet the query remains as to whether this effect is via the promotion of glycogen breakdown and/or the inhibition of glucose uptake. Upon longer term 
administration of acyl-ghrelin in healthy men, at a constant infusion rate lasting 180 minutes at 5 $\mathrm{pmol} / \mathrm{Kg}$, glucose levels were raised but glucose-induced insulin secretion was blocked, with the blockage only being restored when ghrelin supply ceased ${ }^{70}$. However, acyl-ghrelin infusion in healthy humans caused peripheral insulin resistance post administration raising the possibility that insulin resistance may be attributed to raised GH and free fatty acid (FFA) secretion ${ }^{63}$.

The literature indicates that acyl-ghrelin plays a detrimental role in glucose homeostasis, however studies indicate that desacyl-ghrelin plays a beneficiary role. In rodents and humans, desacyl-ghrelin was proven to enhance insulin levels in response to glucose load and shown to counteract acyl-ghrelins diabetogenic effect ${ }^{71-73}$. This a role for desacyl-ghrelin as a potent secretagogue reiterates the importance to consider desacyl and acyl-ghrelin as separate entities and a possible therapeutic pathway may lie within the desacyl-ghrelin and acyl-ghrelin ratio.

\subsubsection{A role for ghrelin in type 2 diabetes?}

An important contributor to the pathophysiology of T2DM is the failure of glucose uptake into the peripheral tissues such as adipose, skeletal muscle and liver. Decreased ghrelin levels within patients with T2DM are associated with an increase in abdominal adiposity and insulin resistance ${ }^{74}$. As previously mentioned ghrelin has a demonstrated role in fat metabolism and glucose homeostasis, and cross talk between lipid and glucose metabolism may result in a physiological role for ghrelin in insulin resistance. Cellular lipid accumulation that is observed upon ghrelin administration will have a knock on effect on glucose homeostasis. There are two hypothesese in place regarding lipid mediated insulin resistance. The first is an excess of visceral adiposity triggers the release of FFA into the circulation. An increase in hepatic FFA oxidation triggers insulin resistance and an increase in glucose output from the liver ${ }^{75,76}$. Acyl-ghrelin infusion in humans has been associated with a rise in circulating FFA levels ${ }^{35}$, this could result in a decrease in insulin sensitivity ${ }^{76}$. These findings suggest a causative role in the reported insulin resistance that occurs in healthy volunteers when given an acyl-ghrelin infusion ${ }^{70,77}$. The second hypothesis is related to enlarged fat laden adipocytes 
associated with release of FFA, physical stress and reactive oxygen species (ROS) production ${ }^{78,79}$. Prolonged elevation of ghrelin increases visceral adiposity in mice and attenuates the transcription of $L X R \beta$ and $A B C G 1$ which increases adipocyte volume due to a reduction in lipid export ${ }^{49}$. LXR isoforms have been reported to have anti-inflammatory properties, LXR ligand activation causes the inhibition of NFKB dependant induction of inflammatory genes ${ }^{80}$. This could allow for altered immune function, due to an increase in ROS and the release of damaging inflammatory agents such as tumor necrosis factor $\alpha(\mathrm{TNF} \alpha)$. When $L \mathrm{Xrab}^{-/}$mice are placed under bacterial lipid peroxidase stress there is an increase in the expression of interlukin $1 \beta$, TNF $\alpha$ and nitric oxide synthase ${ }^{81}$.

This indirect immuno-modulatory response may lead to insulin resistance and T2DM due to TNF $\alpha$ ability to induce the inhibitory phosphorylation of insulin receptor substrate (IRS)-1, leading to systemic insulin resistance ${ }^{79}$. The association between obesity and T2DM is well documented, allowing for ghrelin signalling to play a potential pharmacological role in its prevention and/or treatment. YIL-781 is a piperidine substituted quinazolinone derivative with a selective affinity for GHS-R1 $\alpha$, it is a competitive antagonist for GHS-R1 $\alpha$ resulting in the blockage of the ghrelin binding domain ${ }^{82}$. Upon YIL- 781 oral administration at $3 \mathrm{mg} / \mathrm{kg}$ to insulin resistant DIO rats it was shown to reduce fat mass, enhance glucose stimulated insulin secretion and promote weight loss ${ }^{82}$. Ghrelin's ability to cause hyperglycemia through GHS-R1 $\alpha$ could underpin a therapeutic pathway that can alter insulin secretion and prevent glucose intolerance in T2DM ${ }^{68}$. The attenuation of rat islet $\beta$ cells in the presence of ghrelin indicates that a ghrelin blockade may result in an increase in previously supressed glucose-induced insulin release. This will enable pancreatic islets to function at a higher yield, producing more insulin and restoring the body to normoglycemia ${ }^{83}$. However, the published data regarding the mechanism between ghrelin and insulin secretion is varied within humans. Tong et $\mathrm{al}^{84}$, infused 12 healthy volunteers with ghrelin at $0.3,0.9$ or $1.5 \mathrm{nmol} / \mathrm{kg} / \mathrm{h}$, and show that ghrelin can reduce glucose stimulated insulin secretion. The range of ghrelin in this study fall within the physiological range in the circulation which may not be a true representative of the lower 
concentration of ghrelin found in $\beta$ cells ${ }^{85}$. Further insight in humans or human cells need to be explored in order to investigate species-dependent effects.

Exploration of novel research into ghrelin's relationship with obesity, lipid retention and glucose homeostasis may elucidate novel strategies to treat and prevent T2DM. As well as therapeutic avenues in $\mathrm{T} 2 \mathrm{DM}$, the treatment must take into consideration the physiological roles that ghrelin has in other regions of the body. The blocking of GHS-R1 $\alpha$ may seem beneficial for obesity but may cause detrimental effects in other organs. Recently published data demonstrates that ghrelin has an AMPK-dependent protective role in substantia nigra dopamine neurons in a mouse model of Parkinson's disease ${ }^{86}$. Furthermore, acyl-ghrelin promotes new neurone formation and enhances cognition in the brains of adult rodents ${ }^{87,88}$. With ghrelin reported to have effects on multiple organs in the body it is clear that new ghrelin-based therapies for T2DM need to consider potential adverse consequences, particularly for brain function.

\section{Future work}

In order to establish a possible therapeutic role for ghrelin within human obesity and T2DM previous research findings must be amalgamated and developed further to delineate ghrelin-specific pathways. The examination of the use GHS-R1 $\alpha$ inverse agonist to prevent DIO will require the optimisation of dosage to ensure that blocking the receptor will not have detrimental effects on the other important actions of ghrelin. An in vitro study in human adipocytes would determine the effect that a physiological range of desacyl and acyl-ghrelin has on lipid retention and would allow for the molecular characterisation of this effect. This will lead to a better understanding of the cellular mechanisms involved, potentially leading to novel treatments for complications associated with atherosclerosis and hypertriglyceridemia. For instance, translating previous findings by Davies and colleagues ${ }^{49}$, is important as it could provide evidence for the speculation that ghrelin immunization may prevent lipid retention within adipocytes. As previously mentioned the resultant 
fat laden adipocytes could be detrimental and result in the development of T2DM, so in essence we envision that the prevention of lipid accumulation within adipocytes will prevent the indirect immune modulating response that may be leading to insulin resistance and T2DM. In addition, this area of research requires further insight into whether the effect of ghrelin on adipocytes is dependent on acylation of the hormone.

\section{Summary}

This review considers the important roles that ghrelin plays in regulating lipolysis, lipogenesis and adipogenesis within adipocytes. However, the studies compared in this review were performed in different species and predominantly in rodents. Further work is essential to understand the role of ghrelin in cellular energy balance within human adipocytes. Current literature report variations in route of administration, dosage and model species, allowing for the potential misinterpretation of ghrelin's physiological role. An expansion of this work using healthy and diseased humans and human cellular models treated with physiological levels of acyl and desacyl-ghrelin will increase our current knowledge of the pathways associated with glucose and lipid metabolism. Human studies will also allow for the elucidation of the therapeutic potential of ghrelin in various metabolic disturbances but in particular, DIO and its complications.

\section{Acknowledgements}

I would like to acknowledge Health and care research Wales (HS-14-40) for funding this work.

Conflicts of interest: none.

\section{References}

1 Mishra AK, Dubey V, Ghosh AR. Obesity: An overview of possible role (s) of gut hormones, lipid sensing and gut microbiota. Metabolism. 2016; 65: 48-65. 
3 Meier U, Gressner AM. Endocrine regulation of energy metabolism: review of pathobiochemical and clinical chemical aspects of leptin, ghrelin, adiponectin, and resistin. Clinical Chemistry. 2004; 50: 1511-25.

4 Kojima M, Hosoda H, Date Y, Nakazato M, Matsuo H, Kangawa K. Ghrelin is a growthhormone-releasing acylated peptide from stomach. Nature. 1999; 402: 656-60.

5 Gnanapavan S, Kola B, Bustin SA, Morris DG, McGee P, Fairclough P, et al. The tissue distribution of the mRNA of ghrelin and subtypes of its receptor, GHS-R, in humans. The Journal of Clinical Endocrinology \& Metabolism. 2002; 87: 2988-88.

6 Müller T, Nogueiras R, Andermann M, Andrews Z, Anker S, Argente J, et al. Ghrelin. Molecular Metabolism. 2015; 4: 437-60.

7 Dixit VD, Schaffer EM, Pyle RS, Collins GD, Sakthivel SK, Palaniappan R, et al. Ghrelin inhibits leptin-and activation-induced proinflammatory cytokine expression by human monocytes and $T$ cells. Journal of Clinical Investigation. 2004; 114: 57.

8 Garin MC, Burns CM, Kaul S, Cappola AR. The human experience with ghrelin administration. The Journal of Clinical Endocrinology \& Metabolism. 2013; 98: 1826-37.

$9 \quad$ Angelidis G, Valotassiou V, Georgoulias P. Current and potential roles of ghrelin in clinical practice. Journal of endocrinological investigation. 2010; 33: 823-38.

10 Date Y, Murakami N, Toshinai K, Matsukura S, Niijima A, Matsuo H, et al. The role of the gastric afferent vagal nerve in ghrelin-induced feeding and growth hormone secretion in rats. Gastroenterology. 2002; 123: 1120-28.

11 Rodriguez A, Gomez-Ambrosi J, Catalan V, Gil M, Becerril S, Sainz N, et al. Acylated and desacyl ghrelin stimulate lipid accumulation in human visceral adipocytes. International journal of obesity. 2009; 33: 541-52.

12 Yang J, Brown MS, Liang G, Grishin NV, Goldstein JL. Identification of the acyltransferase that octanoylates ghrelin, an appetite-stimulating peptide hormone. Cell. 2008; 132: 387-96.

13 Banks WA, Tschöp M, Robinson SM, Heiman ML. Extent and direction of ghrelin transport across the blood-brain barrier is determined by its unique primary structure. Journal of Pharmacology and Experimental Therapeutics. 2002; 302: 822-27.

14 Serby MD, Zhao H, Szczepankiewicz BG, Kosogof C, Xin Z, Liu B, et al. 2, 4-diaminopyrimidine derivatives as potent growth hormone secretagogue receptor antagonists. Journal of medicinal chemistry. 2006; 49: 2568-78.

15 Banks WA, Burney BO, Robinson SM. Effects of triglycerides, obesity, and starvation on ghrelin transport across the blood-brain barrier. Peptides. 2008; 29: 2061-65.

16 Tsubone T, Masaki T, Katsuragi I, Tanaka K, Kakuma T, Yoshimatsu H. Ghrelin regulates adiposity in white adipose tissue and UCP1 mRNA expression in brown adipose tissue in mice. Regulatory peptides. 2005; 130: 97-103.

17 Whittle AJ, López M, Vidal-Puig A. Using brown adipose tissue to treat obesity-the central issue. Trends in molecular medicine. 2011; 17: 405-11.

18 Mano-Otagiri A, Iwasaki-Sekino A, Nemoto T, Ohata $H$, Shuto $Y$, Nakabayashi $H$, et al. Genetic suppression of ghrelin receptors activates brown adipocyte function and decreases fat storage in rats. Regulatory peptides. 2010; 160: 81-90.

19 Cai H, Cong W-n, Daimon CM, Wang R, Tschöp MH, Sévigny J, et al. Altered lipid and salt taste responsivity in ghrelin and GOAT null mice. PloS one. 2013; 8: e76553.

20 Masuda Y, Tanaka T, Inomata N, Ohnuma N, Tanaka S, Itoh Z, et al. Ghrelin stimulates gastric acid secretion and motility in rats. Biochemical and biophysical research communications. 2000; 276: 905-08.

21 Cummings DE, Purnell JQ, Frayo RS, Schmidova K, Wisse BE, Weigle DS. A preprandial rise in plasma ghrelin levels suggests a role in meal initiation in humans. Diabetes. 2001; 50: 1714-19. 
22 Brunetti L, Recinella L, Orlando G, Michelotto B, Di Nisio C, Vacca M. Effects of ghrelin and amylin on dopamine, norepinephrine and serotonin release in the hypothalamus. European journal of pharmacology. 2002; 454: 189-92.

23 Broglio F, Gottero C, Benso A, Prodam F, Casanueva FF, Dieguez C, et al. Acetylcholine does not play a major role in mediating the endocrine responses to ghrelin, a natural ligand of the $\mathrm{GH}$ secretagogue receptor, in humans. Clinical endocrinology. 2003; 58: 92-98.

24 Kirchner H, Gutierrez JA, Solenberg PJ, Pfluger PT, Czyzyk TA, Willency JA, et al. GOAT links dietary lipids with the endocrine control of energy balance. Nature medicine. 2009; 15: 741-45. 25 Liu J, Prudom CE, Nass R, Pezzoli SS, Oliveri MC, Johnson ML, et al. Novel ghrelin assays provide evidence for independent regulation of ghrelin acylation and secretion in healthy young men. The Journal of Clinical Endocrinology \& Metabolism. 2008; 93: 1980-87.

26 Broglio F, Arvat E, Benso A, Gottero C, Muccioli G, Papotti M, et al. Ghrelin, a natural GH secretagogue produced by the stomach, induces hyperglycemia and reduces insulin secretion in humans. The Journal of Clinical Endocrinology \& Metabolism. 2001; 86: 5083-83.

27 Chabot F, Caron A, Laplante M, St-Pierre DH. Interrelationships between ghrelin, insulin and glucose homeostasis: Physiological relevance. World journal of diabetes. 2014; 5: 328.

28 Chen L, Xing T, Wang M, Miao Y, Tang M, Chen J, et al. Local infusion of ghrelin enhanced hippocampal synaptic plasticity and spatial memory through activation of phosphoinositide 3-kinase in the dentate gyrus of adult rats. European Journal of Neuroscience. 2011; 33: 266-75.

29 Scerif M, Goldstone AP, Korbonits M. Ghrelin in obesity and endocrine diseases. Molecular and cellular endocrinology. 2011; 340: 15-25.

30 Cowley MA, Smith RG, Diano S, Tschöp M, Pronchuk N, Grove KL, et al. The distribution and mechanism of action of ghrelin in the CNS demonstrates a novel hypothalamic circuit regulating energy homeostasis. Neuron. 2003; 37: 649-61.

31 Arnold M, Mura A, Langhans W, Geary N. Gut vagal afferents are not necessary for the eating-stimulatory effect of intraperitoneally injected ghrelin in the rat. The Journal of neuroscience. 2006; 26: 11052-60.

32 Le Roux C, Neary N, Halsey T, Small C, Martinez-Isla A, Ghatei M, et al. Ghrelin does not stimulate food intake in patients with surgical procedures involving vagotomy. The Journal of Clinical Endocrinology \& Metabolism. 2005; 90: 4521-24.

33 English P, Ghatei M, Malik I, Bloom S, Wilding J. Food fails to suppress ghrelin levels in obese humans. The Journal of Clinical Endocrinology \& Metabolism. 2002; 87: 2984-84.

34 Alvarez-Castro P, Isidro ML, Garcia-Buela J, Leal-Cerro A, Broglio F, Tassone F, et al. Marked $\mathrm{GH}$ secretion after ghrelin alone or combined with $\mathrm{GH}$-releasing hormone $(\mathrm{GHRH})$ in obese patients. Clinical endocrinology. 2004; 61: 250-55.

35 Huda M, Dovey T, Wong S, English P, Halford J, McCulloch P, et al. Ghrelin restores 'leantype'hunger and energy expenditure profiles in morbidly obese subjects but has no effect on postgastrectomy subjects. International Journal of Obesity. 2009; 33: 317-25.

36 Briggs DI, Enriori PJ, Lemus MB, Cowley MA, Andrews ZB. Diet-induced obesity causes ghrelin resistance in arcuate NPY/AgRP neurons. Endocrinology. 2010; 151: 4745-55.

37 Patterson M, Bloom SR, Gardiner JV. Ghrelin and appetite control in humans-potential application in the treatment of obesity. Peptides. 2011; 32: 2290-94.

38 DelParigi A, Tschöp M, Heiman ML, Salbe AD, Vozarova B, Sell SM, et al. High circulating ghrelin: a potential cause for hyperphagia and obesity in Prader-Willi syndrome. The Journal of Clinical Endocrinology \& Metabolism. 2002; 87: 5461-64.

39 Sato T, Ida T, Nakamura Y, Shiimura Y, Kangawa K, Kojima M. Physiological roles of ghrelin on obesity. Obesity research \& clinical practice. 2014; 8: e405-e13.

40 Zorrilla EP, Iwasaki S, Moss JA, Chang J, Otsuji J, Inoue K, et al. Vaccination against weight gain. Proceedings of the National Academy of Sciences. 2006; 103: 13226-31.

41 Hornby P. Designing Spiegelmers to antagonise ghrelin. Gut. 2006; 55: 754-55. 
42 Asakawa A, Inui A, Kaga T, Katsuura G, Fujimiya M, Fujino M, et al. Antagonism of ghrelin receptor reduces food intake and body weight gain in mice. Gut. 2003; 52: 947-52.

43 Maletínská L, Matyšková R, Maixnerová J, Sýkora D, Pýchová $M$, Špolcová $A$, et al. The Peptidic GHS-R antagonist [D-Lys 3] GHRP-6 markedly improves adiposity and related metabolic abnormalities in a mouse model of postmenopausal obesity. Molecular and cellular endocrinology. 2011; 343: 55-62.

44 Holst B, Schwartz TW. Constitutive ghrelin receptor activity as a signaling set-point in appetite regulation. Trends in pharmacological sciences. 2004; 25: 113-17.

45 Petersen PS, Woldbye DP, Madsen AN, Egerod KL, Jin C, Lang M, et al. In vivo characterization of high basal signaling from the ghrelin receptor. Endocrinology. 2009; 150: 492030 .

46 Lee JH, Lin L, Xu P, Saito K, Wei Q, Meadows AG, et al. Neuronal deletion of ghrelin receptor almost completely prevents diet-induced obesity. Diabetes. 2016: db151587.

47 Korbonits M, Goldstone AP, Gueorguiev M, Grossman AB. Ghrelin-a hormone with multiple functions. Frontiers in neuroendocrinology. 2004; 25: 27-68.

48 Knebel B, Haas J, Hartwig S, Jacob S, Köllmer C, Nitzgen U, et al. Liver-specific expression of transcriptionally active SREBP-1c is associated with fatty liver and increased visceral fat mass. PloS one. 2012; 7: e31812.

49 Davies JS, Kotokorpi P, Eccles SR, Barnes SK, Tokarczuk PF, Allen SK, et al. Ghrelin induces abdominal obesity via GHS-R-dependent lipid retention. Molecular Endocrinology. 2009; 23: 914-24.

50 Kennedy MA, Barrera GC, Nakamura K, Baldán Á, Tarr P, Fishbein MC, et al. ABCG1 has a critical role in mediating cholesterol efflux to HDL and preventing cellular lipid accumulation. Cell metabolism. 2005; 1: 121-31.

51 Fielding CJ, Fielding PE. Cellular cholesterol efflux. Biochimica et Biophysica Acta (BBA)Molecular and Cell Biology of Lipids. 2001; 1533: 175-89.

52 Vaughan AM, Oram JF. ABCG1 redistributes cell cholesterol to domains removable by high density lipoprotein but not by lipid-depleted apolipoproteins. Journal of Biological Chemistry. 2005; 280: 30150-57.

53 Ma AZ, Song ZY, Zhang Q. Cholesterol efflux is LXRalpha isoform-dependent in human Macrophages. BMC cardiovascular disorders. 2014; 14: 80.

54 Wagner BL, Valledor AF, Shao G, Daige CL, Bischoff ED, Petrowski M, et al. Promoter-specific roles for liver $\mathrm{X}$ receptor/corepressor complexes in the regulation of ABCA1 and SREBP1 gene expression. Molecular and cellular biology. 2003; 23: 5780-89.

55 Porteiro B, Díaz-Ruíz A, Martínez G, Senra A, Vidal A, Serrano M, et al. Ghrelin requires p53 to stimulate lipid storage in fat and liver. Endocrinology. 2013; 154: 3671-79.

56 Velásquez DA, Martínez G, Romero A, Vázquez MJ, Boit KD, Dopeso-Reyes IG, et al. The central Sirtuin 1/p53 pathway is essential for the orexigenic action of ghrelin. Diabetes. 2011; 60: 1177-85.

57 Kola B, Wittman G, Bodnár I, Amin F, Lim CT, Oláh M, et al. The CB1 receptor mediates the peripheral effects of ghrelin on AMPK activity but not on growth hormone release. The FASEB Journal. 2013; 27: 5112-21.

58 Demers A, Caron V, Rodrigue-Way A, Wahli W, Ong H, Tremblay A. A concerted kinase interplay identifies PPARY as a molecular target of ghrelin signaling in macrophages. 2009.

59 Schultz JR, Tu H, Luk A, Repa JJ, Medina JC, Li L, et al. Role of LXRs in control of lipogenesis. Genes \& development. 2000; 14: 2831-38.

60 Benso A, St-Pierre D, Prodam F, Gramaglia E, Granata R, van der Lely AJ, et al. Metabolic effects of overnight continuous infusion of unacylated ghrelin in humans. European Journal of Endocrinology. 2012; 166: 911-16.

61 Gasco V, Beccuti G, Marotta F, Benso A, Granata R, Broglio F, et al. Endocrine and metabolic actions of ghrelin. 2010. 
62 Kageyama H, Funahashi H, Hirayama M, Takenoya F, Kita T, Kato S, et al. Morphological analysis of ghrelin and its receptor distribution in the rat pancreas. Regulatory peptides. 2005; 126: 67-71.

63 Delhanty P, van der Lely AJ. Ghrelin and glucose homeostasis. Peptides. 2011; 32: 2309-18. 64 Dezaki K, Hosoda H, Kakei M, Hashiguchi S, Watanabe M, Kangawa K, et al. Endogenous ghrelin in pancreatic islets restricts insulin release by attenuating $\mathrm{Ca} 2+$ signaling in $\beta$-cells implication in the glycemic control in rodents. Diabetes. 2004; 53: 3142-51.

65 DiGruccio MR, Mawla AM, Donaldson CJ, Noguchi GM, Vaughan J, Cowing-Zitron C, et al. Comprehensive alpha, beta and delta cell transcriptomes reveal that ghrelin selectively activates delta cells and promotes somatostatin release from pancreatic islets. Molecular Metabolism. 2016. 66 Broglio F, Gottero C, Benso A, Prodam F, Destefanis S, Gauna C, et al. Effects of ghrelin on the insulin and glycemic responses to glucose, arginine, or free fatty acids load in humans. The Journal of Clinical Endocrinology \& Metabolism. 2003; 88: 4268-72.

67 Guido M, Romualdi D, De Marinis L, Porcelli T, Giuliani M, Costantini B, et al. Administration of exogenous ghrelin in obese patients with polycystic ovary syndrome: effects on plasma levels of growth hormone, glucose, and insulin. Fertility and sterility. 2007; 88: 125-30.

68 Dezaki K, Sone H, Yada T. Ghrelin is a physiological regulator of insulin release in pancreatic islets and glucose homeostasis. Pharmacology \& therapeutics. 2008; 118: 239-49.

69 Arosio M, Ronchi CL, Gebbia C, Cappiello V, Beck-Peccoz P, Peracchi M. Stimulatory effects of ghrelin on circulating somatostatin and pancreatic polypeptide levels. The Journal of Clinical Endocrinology \& Metabolism. 2003; 88: 701-04.

70 Vestergaard ET, Hansen TK, Gormsen LC, Jakobsen P, Moller N, Christiansen JS, et al. Constant intravenous ghrelin infusion in healthy young men: clinical pharmacokinetics and metabolic effects. American Journal of Physiology-Endocrinology and Metabolism. 2007; 292: E1829-E36.

71 Gauna C, Kiewiet RM, Janssen JA, van de Zande B, Delhanty PJ, Ghigo E, et al. Unacylated ghrelin acts as a potent insulin secretagogue in glucose-stimulated conditions. American Journal of Physiology-Endocrinology and Metabolism. 2007; 293: E697-E704.

72 Delhanty PJ, Neggers SJ, van der Lely AJ. Should we consider des-acyl ghrelin as a separate hormone and if so, what does it do? How Gut and Brain Control Metabolism. Karger Publishers 2014; 163-74.

73 Delhanty P, van der Lely A-J. Ghrelin and glucose homeostasis. Peptides. 2011; 32: 2309-18.

74 Katsuki A, Urakawa H, Gabazza EC, Murashima S, Nakatani K, Togashi K, et al. Circulating levels of active ghrelin is associated with abdominal adiposity, hyperinsulinemia and insulin resistance in patients with type 2 diabetes mellitus. European Journal of Endocrinology. 2004; 151: 573-77.

75 Lam TK, Van de Werve G, Giacca A. Free fatty acids increase basal hepatic glucose production and induce hepatic insulin resistance at different sites. American Journal of PhysiologyEndocrinology And Metabolism. 2003; 284: E281-E90.

76 Boden G. Free fatty acids, insulin resistance, and type 2 diabetes mellitus. Proceedings of the Association of American Physicians. 1999; 111: 241-48.

77 Vestergaard ET, Buhl M, Gjedsted J, Madsen M, Jessen N, Nielsen S, et al. Acute peripheral metabolic effects of intraarterial ghrelin infusion in healthy young men. The Journal of Clinical Endocrinology \& Metabolism. 2010; 96: 468-77.

78 Maumus M, Sengenes C, Decaunes P, Zakaroff-Girard A, Bourlier V, Lafontan M, et al. Evidence of in situ proliferation of adult adipose tissue-derived progenitor cells: influence of fat mass microenvironment and growth. The Journal of Clinical Endocrinology \& Metabolism. 2008; 93: 4098106.

79 Gustafson B. Adipose tissue, inflammation and atherosclerosis. Journal of atherosclerosis and thrombosis. 2010; 17: 332-41.

80 Zelcer $\mathrm{N}$, Tontonoz $\mathrm{P}$. Liver $\mathrm{X}$ receptors as integrators of metabolic and inflammatory signaling. The Journal of clinical investigation. 2006; 116: 607-14. 
81 Joseph SB, Castrillo A, Laffitte BA, Mangelsdorf DJ, Tontonoz P. Reciprocal regulation of inflammation and lipid metabolism by liver $X$ receptors. Nature medicine. 2003; 9: 213-19.

82 Esler WP, Rudolph J, Claus TH, Tang W, Barucci N, Brown S-E, et al. Small-molecule ghrelin receptor antagonists improve glucose tolerance, suppress appetite, and promote weight loss. Endocrinology. 2007; 148: 5175-85.

83 Dezaki K, Yada T. Islet b-cell ghrelin signaling for inhibition of insulin secretion. Methods Enzymol. 2012; 514: 317-31.

84 Tong J, Prigeon RL, Davis HW, Bidlingmaier M, Kahn SE, Cummings DE, et al. Ghrelin suppresses glucose-stimulated insulin secretion and deteriorates glucose tolerance in healthy humans. Diabetes. 2010; 59: 2145-51.

85 Meyer $C$. Final answer: ghrelin can suppress insulin secretion in humans, but is it clinically relevant? Diabetes. 2010; 59: 2726-28.

86 Bayliss JA, Lemus MB, Stark R, Santos VV, Thompson A, Rees DJ, et al. Ghrelin-AMPK Signaling Mediates the Neuroprotective Effects of Calorie Restriction in Parkinson's Disease. The Journal of Neuroscience. 2016; 36: 3049-63.

87 Hornsby AK, Redhead YT, Rees DJ, Ratcliff MS, Reichenbach A, Wells T, et al. Short-term calorie restriction enhances adult hippocampal neurogenesis and remote fear memory in a Ghsrdependent manner. Psychoneuroendocrinology. 2016; 63: 198-207.

88 Kent BA, Beynon AL, Hornsby AK, Bekinschtein P, Bussey TJ, Davies JS, et al. The orexigenic hormone acyl-ghrelin increases adult hippocampal neurogenesis and enhances pattern separation. Psychoneuroendocrinology. 2015; 51: 431-39.

89 Tong J, Davis HW, Summer S, Benoit SC, Haque A, Bidlingmaier M, et al. Acute administration of unacylated ghrelin has no effect on Basal or stimulated insulin secretion in healthy humans.

Diabetes. 2014; 63: 2309-19.

90 Heppner KM, Piechowski CL, Müller A, Ottaway N, Sisley S, Smiley DL, et al. Both acyl and des-acyl ghrelin regulate adiposity and glucose metabolism via central nervous system ghrelin receptors. Diabetes. 2014; 63: 122-31.

91 Miegueu P, St Pierre D, Broglio F, Cianflone K. Effect of desacyl ghrelin, obestatin and related peptides on triglyceride storage, metabolism and GHSR signaling in 3T3-L1 adipocytes. Journal of cellular biochemistry. 2011; 112: 704-14. 


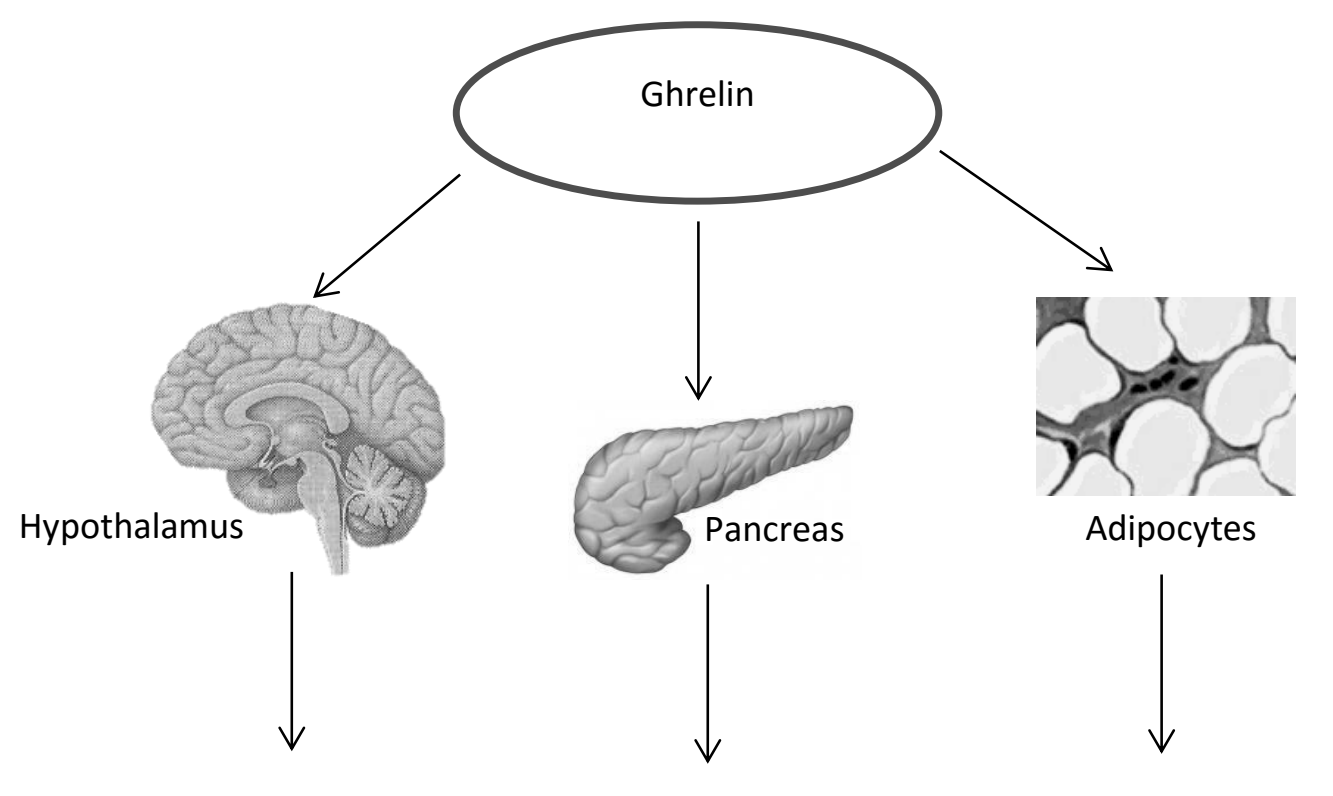

Appetite/Obesity Glucose metabolism Adipogenesis/Lipid retention

Figure 1. Ghrelin peripheral effects on specific tissues. 


\begin{tabular}{|c|c|c|c|c|}
\hline Model & Dose & Treatment & Effect & Reference \\
\hline Healthy humans & $\begin{array}{l}1 \mu \mathrm{g} / \mathrm{kg} \\
\text { Acyl ghrelin }\end{array}$ & Intravenous & $\begin{array}{l}\text { Decreased Insulin } \\
\text { Sensitivity } \\
\text { Reduced serum } \\
\text { insulin levels }\end{array}$ & 26 \\
\hline Healthy humans & $\begin{array}{l}\text { Bolus; } \\
\text { Des acyl ghrelin } \\
{[1.1 \mu \mathrm{g} / \mathrm{kg}]} \\
\text { IV; } \\
\text { Des acyl ghrelin } \\
{[4.0 \mu \mathrm{g} / \mathrm{kg} / \mathrm{h}]}\end{array}$ & $\begin{array}{l}\text { Bolus injection followed } \\
\text { by continuous } \\
\text { intravenous infusion }\end{array}$ & $\begin{array}{l}\text { Des acyl ghrelin } \\
\text { had no effect on } \\
\text { insulin secretion }\end{array}$ & 89 \\
\hline $\begin{array}{l}\text { Male C57BL/6 } \\
\text { mice }\end{array}$ & $\begin{array}{l}5 \mathrm{nmol} / \text { day } \\
\text { Des acyl ghrelin } \\
\text { \& Acyl ghrelin }\end{array}$ & $\begin{array}{l}\text { Chronic } \\
\text { intracerebroventricular } \\
\text { infusion }\end{array}$ & Hyperinsulinemia & 90 \\
\hline $\begin{array}{l}\text { Human } \\
\text { macrophages } \\
\text { (THP-1) }\end{array}$ & $\begin{array}{l}1,10 \& 100 \mathrm{nM} \\
\text { ghrelin }\end{array}$ & $\begin{array}{l}\text { Treated PMA- } \\
\text { differentiated THP-1 } \\
\text { macrophages with } \\
\text { increasing doses of } \\
\text { ghrelin }\end{array}$ & $\begin{array}{l}\text { Promotes } \\
\text { activation of the } \\
\text { Akt/PKB pathway }\end{array}$ & 58 \\
\hline 3T3-L1 & $\begin{array}{l}\text { Acyl ghrelin 1- } \\
100 \text { pmol, } \\
\text { Des Acyl ghrelin } \\
1-100 \text { pmol }\end{array}$ & $\begin{array}{l}\text { Preadipocytes incubated } \\
\text { with des acyl ghrelin and } \\
\text { acyl ghrelin for } 24 \text { hours }\end{array}$ & $\begin{array}{l}\text { DAG and AG } \\
\text { stimulated } \\
\text { adipogenesis, fatty } \\
\text { acid uptake and } \\
\text { inhibited lipolysis }\end{array}$ & 91 \\
\hline $\begin{array}{l}\text { C57BL/6NHsd } \\
\text { mice }\end{array}$ & 100 nM Ghrelin & $\begin{array}{l}\text { Wild type mouse } \\
\text { pancreatic islets } \\
\text { incubated with ghrelin }\end{array}$ & $\begin{array}{l}\text { Reduced glucose } \\
\text { stimulated insulin } \\
\text { secretion }\end{array}$ & 65 \\
\hline
\end{tabular}

Table 1. Effects of ghrelin treatment on insulin secretion and adipogenesis. 